\title{
Toward Greener Synthesis of WC Powders for Cemented Tungsten Carbides Manufacturing
}

\author{
Riccardo Polini,* Andrea Marcucci, Cadia D’Ottavi, Patrizia Nunziante, Paolo De Filippis, \\ and GianCarlo Marcheselli
}

Cite This: ACS Sustainable Chem. Eng. 2021, 9, 8458-8466

Read Online

\section{ACCESS | Llll Metrics \& More | 国 Article Recommendations | Sl Supporting Information}

ABSTRACT: Tungsten carbide (WC) is the most important tungsten compound, and the main component of WC-Co cermet composites. WC-Co are widely used engineering materials due to the combination of high hardness and strength of tungsten carbide with the toughness and plasticity of the metallic binder. The direct synthesis of WC from tungsten concentrate containing $\sim 70 \% \mathrm{WO}_{3}$ has been achieved by carbothermic reduction. Mineral/carbon black mixtures were prepared by planetary ball milling and subjected to annealing at $1150{ }^{\circ} \mathrm{C}$ in flowing Ar. Specific leaching treatments have been developed to remove foreign phases and obtain pure WC powders. This new process allows about $50 \%$ energy saving, $-34 \% \mathrm{CO}_{2}$ emissions, and significantly lower amounts of industrial waste, with respect to the classical

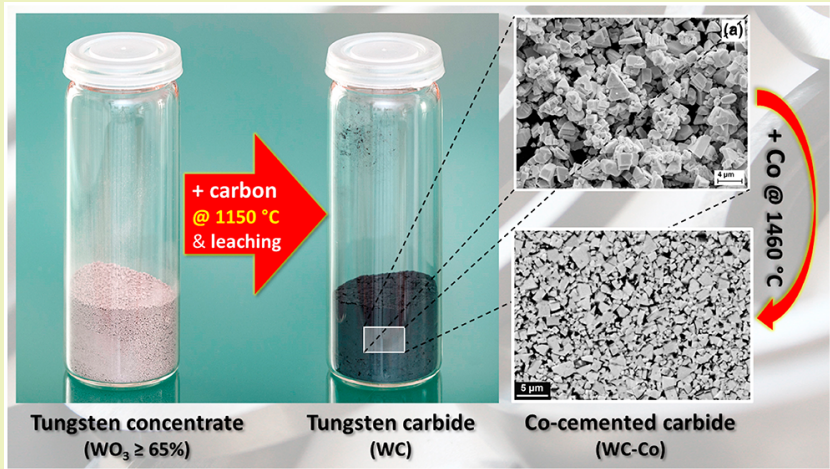
hydrometallurgical tungsten extraction and subsequent pyrometallurgical WC synthesis, widely used in tungsten industry. WC powders obtained by carbothermic reduction of the mineral were employed to prepare sintered WC-8 wt \%Co samples that showed high density (>99\%), hardness (1490 HV), and toughness (14.6 $\left.\mathrm{MPa} \cdot \mathrm{m}^{1 / 2}\right)$. These findings demonstrate, for the first time, that the carbothermic reduction of tungsten concentrates does represent a viable process for energy efficient and sustainable synthesis of WC powders to be used in the production of cemented carbides.

KEYWORDS: Carbothermic reduction, Tungsten concentrate, Scheelite, Wolframite, Tungsten carbide powders, Sintering, Cemented carbides, Sustainability

\section{INTRODUCTION}

Tungsten is a rare chemical element, being $1.3 \mathrm{ppm}$ its estimated abundance in the Earth's crust. ${ }^{1}$ Tungsten does not occur naturally as a free metal. The most important economically interesting tungsten ores are scheelite (calcium tungstate, $\mathrm{CaWO}_{4}$ ) and wolframite (a solid solution or a mixture of the isomorphous substances ferrous tungstate, $\mathrm{FeWO}_{4}$, and manganous tungstate, $\mathrm{MnWO}_{4}$ ). Scheelite accounts for approximately two-thirds of known tungsten deposits and remains the most important raw material for the manufacturing of pure $\mathrm{W}$ metal and tungsten compounds. The average concentration in workable ores is usually between 0.1 and $1.0 \%$ tungsten trioxide $\left(\mathrm{WO}_{3}\right)$. The first phase of processing the ore at the mine site is the separation of tungstates from the gangue (or waste rock) by physical beneficiation methods and thereby increasing the tungsten content. The resulting tungsten concentrate contains typically $60-75 \% \mathrm{WO}_{3}\left(\mathrm{WO}_{3}\right.$ content of pure scheelite and wolframite is $80.6 \%$ and $76.5 \%$, respectively) Due to the increasingly complex mineralogy of tungsten ores, the tungsten concentrate contains frequently a mixture of scheelite and wolframite. ${ }^{2}$
Despite its scarcity, the total tungsten market demand is around $10^{5}$ ton/year. About $54-72 \%$ of the tungsten produced globally is employed as monocarbide, WC, to manufacture cemented tungsten carbides (WC-Co, also called "hard metals") by powder metallurgy. ${ }^{1-3}$ Hard metals are a range of cermet composites consisting of tungsten carbide grains bonded together by a metallic binder. The proportion of carbide phase is normally $70-97 \%$ of the total mass of the composite. The excellent wetting ability of tungsten carbide with cobalt has made this metal the first choice as binder. Cemented carbides have outstanding properties due to the combination of high hardness and strength of WC with the toughness and plasticity of the metallic binder. This unique combination of hardness and toughness make them the best choice for manufacturing components that must provide

Received: February 23, 2021

Revised: June 3, 2021

Published: June 15, 2021 
Table 1. WD-XRF Analysis of the Tungsten Concentrate

$\begin{array}{llllllllllll}\text { composition } & \mathrm{WO}_{3} & \mathrm{CaO} & \mathrm{Fe}_{2} \mathrm{O}_{3} & \mathrm{SiO}_{2} & \mathrm{MnO} & \mathrm{F} & \mathrm{ZrO}_{2} & \mathrm{SO}_{3} & \mathrm{Al}_{2} \mathrm{O}_{3} & \mathrm{TiO}_{2} & \mathrm{MgO} \\ \text { mass fraction \% } & 69.9 & 16.4 & 4.25 & 2.62 & 2.05 & 0.88 & 0.65 & 0.51 & 0.43 & 0.29 & 0.11 \\ \text { composition } & \mathrm{Bi}_{2} \mathrm{O}_{3} & \mathrm{SnO}_{2} & \mathrm{P}_{2} \mathrm{O}_{5} & \mathrm{~K}_{2} \mathrm{O} & \mathrm{CuO} & \mathrm{SrO} & \mathrm{Nb}_{2} \mathrm{O}_{5} & \mathrm{NiO} & \mathrm{Co}_{3} \mathrm{O}_{4} & \mathrm{Cr}_{2} \mathrm{O}_{3} & \mathrm{Y}_{2} \mathrm{O}_{3} \\ \text { mass fraction \% } & 0.32 & 0.14 & 0.11 & 0.076 & 0.064 & 0.072 & 0.050 & 0.11 & 0.097 & 0.10 & 0.017\end{array}$

longer life in applications where other materials would fail prematurely (metal cutting; machining of wood, plastics, composites, and soft ceramics; chipless forming; mining and construction; structural parts; wear parts). ${ }^{4}$

The currently employed hydrometallurgical route to extract $\mathrm{W}$ from the tungsten concentrate leads to the synthesis of pure ammonium paratungstate $\left(\mathrm{APT},\left(\mathrm{NH}_{4}\right)_{10}\left(\mathrm{~W}_{12} \mathrm{O}_{41}\right) \cdot x \mathrm{H}_{2} \mathrm{O}\right)$ via multiple treatments (pressure leaching, filtration, solvent extraction, precipitation), which generate lots of effluents that represent an environmental hazard. The further cost of effluent treatments adds to the overall cost. ${ }^{5,6} \mathrm{APT}$ is the main intermediate and the main tungsten raw material traded in the market. Following its synthesis by hydrometallurgical route, APT is subjected to pyrometallurgy, that is, calcination at 300-800 ${ }^{\circ} \mathrm{C}$ to yellow trioxide $\left(\mathrm{WO}_{3}\right)$ or blue oxide $\left(\mathrm{WO}_{3-x}\right)^{6}$ Tungsten metal powder is then produced from $\mathrm{WO}_{3}$ or $\mathrm{WO}_{3-x}$ in hydrogen reduction furnaces, at 700-1000 ${ }^{\circ} \mathrm{C}$. Tungsten carbide is finally produced by carburization of tungsten metal powder with carbon black at $1400-1800{ }^{\circ} \mathrm{C}$. It is possible to estimate a total energy consumption of $16 \mathrm{MWh}$ to produce 1 ton of WC from the tungsten concentrate. ${ }^{7,8}$ Most of this energy is spent in the high temperature, energydemanding steps necessary to convert APT into WC (APT $\rightarrow$ $\mathrm{WO}_{3} \rightarrow \mathrm{W} \rightarrow \mathrm{WC}$ ). A way to reduce the energy consumption is the fabrication of tungsten carbide powders via carbothermic reduction of tungsten oxide $\left(\mathrm{WO}_{3}+4 \mathrm{C} \rightarrow \mathrm{WC}+3 \mathrm{CO}\right)$. This process can be optimized to prepare high-purity WC particles with different size, as shown recently by Wand et al. ${ }^{9,10}$ However, the starting material is $\mathrm{WO}_{3}$, industrially prepared by calcination of APT, which in turn is obtained by the abovementioned multiple treatments described in ref 6 .

Any process that synthesizes WC by using less energy and producing lesser amounts of industrial waste is expected to be both more economical and in accordance with Goal 12 (sustainable consumption and production) of the UN Agenda 2030 for Sustainable Development. ${ }^{11}$

Several papers have described the direct synthesis of WC powders from tungsten ores, which promises to be less costly and environmentally friendly. N. J. Welham ${ }^{12,13}$ studied the carbothermic reduction of a stoichiometric mixture of graphite and scheelite. The scheelite ore contained $\sim 4 \mathrm{wt} \%$ quartz, and other impurities $\leq 0.1 \%$. He found that scheelite in mixtures subjected to $40 \mathrm{~h}$ milling could be quantitatively converted into submicrometer WC powders after $1 \mathrm{~h}$ at $1000-1100{ }^{\circ} \mathrm{C}$, according to reaction 1 :

$$
\mathrm{CaWO}_{4(\mathrm{~s})}+4 \mathrm{C}_{(\mathrm{s})} \rightarrow \mathrm{CaO}_{(\mathrm{s})}+\mathrm{WC}_{(\mathrm{s})}+3 \mathrm{CO}_{(\mathrm{g})}
$$

$\mathrm{CaO}$ was subsequently removed by $1 \mathrm{~h}$ leaching with $0.1 \mathrm{M}$ $\mathrm{HCl}$. However, the author did not give information on the phase purity of the WC powder; in fact, quartz contained in the enriched ore and silicon-bearing phases that could have been formed during the carbothermic reduction are not soluble in diluted $\mathrm{HCl}$.

The positive role of high-energy milling was confirmed by Temuujin et al. for the carbothermic reduction of natural wolframite. ${ }^{14}$ The natural wolframite contained $71.85 \% \mathrm{WO}_{3}$ and 1.1 wt \% silica. After planetary ball milling and $1 \mathrm{~h}$ carbothermic reduction at $1100{ }^{\circ} \mathrm{C}$, WC nanoparticles were obtained. However, the synthesized $\mathrm{WC}$ was neither phase pure (small amounts of $\mathrm{Fe}, \mathrm{Fe}_{3} \mathrm{C}, \mathrm{Fe}_{7} \mathrm{~W}_{6}, \mathrm{Fe}_{3} \mathrm{~W}_{3} \mathrm{C}$, and $\mathrm{W}$ were formed alongside $\mathrm{WC}$ ) nor purified to remove secondary phases (e.g., silica).

Singh and Pandey ${ }^{15}$ reported the synthesis of nanocrystalline WC by carbothermic reduction $\left(4 \mathrm{~h}\right.$ at $1025{ }^{\circ} \mathrm{C}$ under flowing argon gas) of scheelite ore ball-milled up to $100 \mathrm{~h}$ with activated charcoal. After two-step leaching with 1:1 $\mathrm{HCl}$ and $0.25 \mathrm{M} \mathrm{NaOH}$, the resulting powder showed only WC X-ray diffraction (XRD) peaks. However, these authors employed a very large excess of carbon $\left(\mathrm{CaWO}_{4} / \mathrm{C}=1: 2\right.$ weight ratio), that is, twelve times the stoichiometric quantity of carbon required by reaction 1 ; a significant amount of charcoal, which does not show well-defined XRD peaks, should have remained in the final WC powder. Consequently, the as-prepared powder was not appropriate for hard metal sintering.

The aim of this study is threefold. First, we present a detailed procedure for the preparation of WC powders by carbothermic reduction of tungsten concentrate and subsequent leaching treatments. Then, we show that the obtained WC can be sintered with cobalt binder to produce dense hard metal with mechanical properties suitable for industrial use. Finally, for the very first time we estimate energy consumptions, $\mathrm{CO}_{2}$ emissions and amount of industrial waste associated with the synthesis of WC by carbothermic reduction of tungsten concentrate. These figures are compared to the conventional hydro- and pyrometallurgical routes and confirm that the carbothermic synthesis of WC powders is preferable from a sustainability point of view.

\section{MATERIALS AND METHODS}

The tungsten concentrate used in this study was analyzed by Wavelength Dispersive X-ray Fluorescence (WD-XRF, PANalytical, model Zetium) and $\theta / 2 \theta$ powder X-ray diffraction (XRD, Philips, model X'Pert Pro, $\mathrm{Cu} \mathrm{K} \alpha$ radiation, $\lambda=1.5418 \AA$ ). The results of WD-XRF analysis are shown in Table 1.

XRD pattern in Figure 1 showed that $\mathrm{CaWO}_{4}$ (JCPDS card no. 41-1431) was distinctly the most abundant phase in the tungsten concentrate. Wolframite $\left(\mathrm{Fe}_{1-x} \mathrm{Mn}_{x} \mathrm{WO}_{4}\right)$ was also present (JCPDS card no. 46-1446). Other detectable crystalline phases were quartz $\left(\mathrm{SiO}_{2}, \mathrm{JCPDS}\right.$ card no. 46-1045) and silicates. Very weak peaks, marked with an asterisk, could not be correctly assigned (in Figure 1 we used the square root of the intensity, in order to make weak peaks more clearly visible).

The carbon source for the carbothermic reduction of the tungsten concentrate was carbon black (Thermax N990 supplied by Carbon Ltd.) obtained by thermal decomposition of natural gas.

Four mineral/carbon mixtures were prepared with weight ratios equal to 100:14.5 (corresponding to the stoichiometric quantity of carbon required for complete formation of $\mathrm{CaO}$ and $\mathrm{WC}$, according to the $\mathrm{WO}_{3}$ content determined by XRF), 100:14.8, 100:15.0 and 100:15.2. Powders were loaded in a planetary ball mill (Retsch PM 400). In particular, $100 \mathrm{~g}$ of powder were loaded in a $500 \mathrm{~mL}$ capacity tungsten carbide grinding jar with $700 \mathrm{~g}$ of $4 \mathrm{~mm}$ diameter hardmetal balls (ball/powder mass ratio of 7:1) and $150 \mathrm{~mL}$ of 2-propanol. The powder mixture was ball-milled for $24 \mathrm{~h}$, with a rotation speed of 300 rpm. 


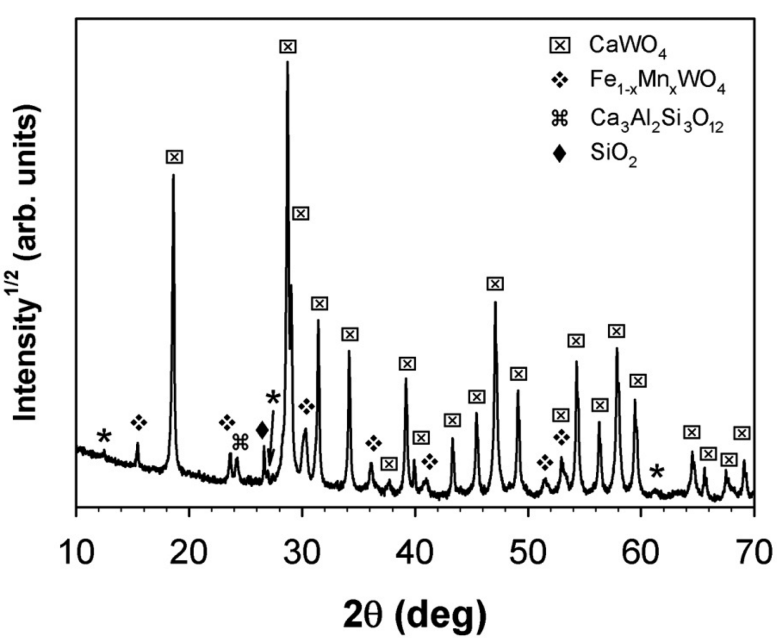

Figure 1. X-ray diffraction pattern $(\mathrm{Cu} K \alpha)$ of the tungsten concentrate. Peaks marked with an asterisk could not be properly assigned.

Thermogravimetric analysis (TGA) and simultaneous differential thermal analysis (DTA) were performed on milled powders using samples of approximately $50 \mathrm{mg}$ in an alumina crucible. The powders were heated up to $1250{ }^{\circ} \mathrm{C}$ in a pure nitrogen (99.9995\%) atmosphere $(100 \mathrm{~mL} / \mathrm{min})$ at a rate of $10{ }^{\circ} \mathrm{C} / \mathrm{min}$ using a Stanton Redcroft STA 1500 instrument.

Larger amounts ( $200 \mathrm{~g})$ of milled mixtures were loaded in graphite boats and subjected to carbothermic reaction in a tubular furnace for $6 \mathrm{~h}$ at $1150{ }^{\circ} \mathrm{C}$ (heating rate $3{ }^{\circ} \mathrm{C} / \mathrm{min}$ ) under flowing argon $(100 \mathrm{~L} / \mathrm{h})$. After carbothermic reduction, the synthesized WC powders were purified by two-step leaching. The first leaching step was performed in boiling $\mathrm{HCl} \sim 6 \mathrm{M}$ for $4 \mathrm{~h}$ to dissolve $\mathrm{CaO}$ and other phases potentially soluble in hydrochloric acid. The $\mathrm{HCl}$ / powder weight ratio was $15: 1$. In order to dissolve silicon-bearing phases, a second leaching step was done using concentrated HF (50\%, Carlo Erba Reagents), under stirring at room temperature for 135 min. The HF/powder weight ratio was approximately 2.5:1. After each leaching treatment, the powder was filtrated, washed with deionized water, rinsed with ethanol to remove water, and then dried overnight at $80{ }^{\circ} \mathrm{C}$.

The phase composition of the samples was assessed by $\theta / 2 \theta \mathrm{X}$-ray diffraction (XRD) with a Philips X'Pert Pro diffractometer, equipped with a plane monochromator using $\mathrm{Cu} K \alpha$ radiation $(\lambda=1.5418 \AA)$. Diffraction patterns were acquired using a count time of $1 \mathrm{~s}$ per $0.02^{\circ}$ step. Selected powders were imaged using a LEO Supra 35 field emission gun scanning electron microscope (FEG SEM, Carl Zeiss AG) incorporating energy-dispersive X-ray spectroscopy (EDS, Oxford Instruments Ltd., model Inca 300).

The content of impurities in tungsten carbide powder obtained by carbothermic reduction and used in the preparation of sintered samples was determined by inductively coupled plasma-atomic emission spectroscopy (ICP-AES; Horiba Jobin Yvon, model JY 2000-2). Before ICP-AES analysis, $\sim 600 \mathrm{mg}$ of WC powder were solubilized in hot $\mathrm{HNO}_{3} / \mathrm{HF}=1: 1$ mixture $(20 \mathrm{~mL})$.

WC powder was subjected to liquid-phase sintering to prepare 92WC-8Co (wt \%) hard metal samples. The metallic binder and tungsten carbide powder were wet mixed in 2-propanol containing $2 \%$ organic binder referred to the total mass of the charge and ball-milled for $72 \mathrm{~h}$. The dried cakes were crushed and sieved to 20 mesh granules. They were formed into rectangular bars in a hard die at 1 ton $/ \mathrm{cm}^{2}$ using a Dorst TPA-12 press. Prior to sintering, the green bars were submitted to a two-step presintering thermal treatment $(3 \mathrm{~h}$ at $450{ }^{\circ} \mathrm{C}+1 \mathrm{~h}$ at $700{ }^{\circ} \mathrm{C}$ ) in an atmosphere containing $75 \mathrm{vol} \% \mathrm{H}_{2}$ and $25 \mathrm{vol} \% \mathrm{~N}_{2}$. Then the samples were submitted to $1 \mathrm{~h}$ sinter-HIP (a process combining sintering and hot isostatic pressing into a single operation) at $1460{ }^{\circ} \mathrm{C}$ in argon $(3.5 \mathrm{MPa})$. The density of the sintered cemented carbides was measured by Archimedes method.
Hardness of the materials was determined according to Vickers (HV30) and Rockwell A (HRA) at room temperature. The fracture toughness $\left(K_{\mathrm{IC}}\right)$ was evaluated by the equation $K_{\mathrm{IC}}=0.0028(\mathrm{HV} 30$. $F / L)^{1 / 2}$, where $L$ is the total length of the cracks generated by the Vickers indentation, HV30 is the Vickers hardness, and $F$ is the applied force. ${ }^{16}$

Mirror-polished sintered samples were characterized by FEG-SEM.

The material and in situ energy demand of the direct synthesis of tungsten carbide was estimated on the basis of laboratory data. The calculations are referred to an output of the process of 1 metric ton of WC and considering as feed an enriched mineral ore with a $\mathrm{WO}_{3}$ content of $68 \%$. The energy required for the ball milling of tungsten ore with carbon black was estimated from the equation of Bond ${ }^{17}$ assuming a work index for the comminution of tungsten ore equal to $14 \mathrm{kWh} / \mathrm{t}^{18}$ The energy demand of the carbothermic step was calculated from the enthalpy of reaction $1\left(\Delta H_{\mathrm{r}}^{\circ}=638.8 \mathrm{~kJ} / \mathrm{mol}\right)$ and keeping into account the sensible heat necessary to bring the reagents and argon to the selected reduction temperature of $1150{ }^{\circ} \mathrm{C}$. The thermodynamic data were taken from Barin. ${ }^{19}$ The energy required to heat the furnace to the selected temperature was deducted from manufacturers' data $(560 \mathrm{kWh})$. The thermal efficiency of the reduction furnace heated from inside by electric power was assumed to a value of approximately $70 \%$. The energy required to recover, through distillation, the excess of leaching acids was calculated using AVEVA PRO/II process simulator. The handling of solid and liquids was assumed equal to $15 \%$ of that energy.

\section{RESULTS AND DISCUSSION}

TGA-DTA. Figure 2 displays the simultaneous TGA-DTA profiles of mineral/C mixtures containing the minimum and

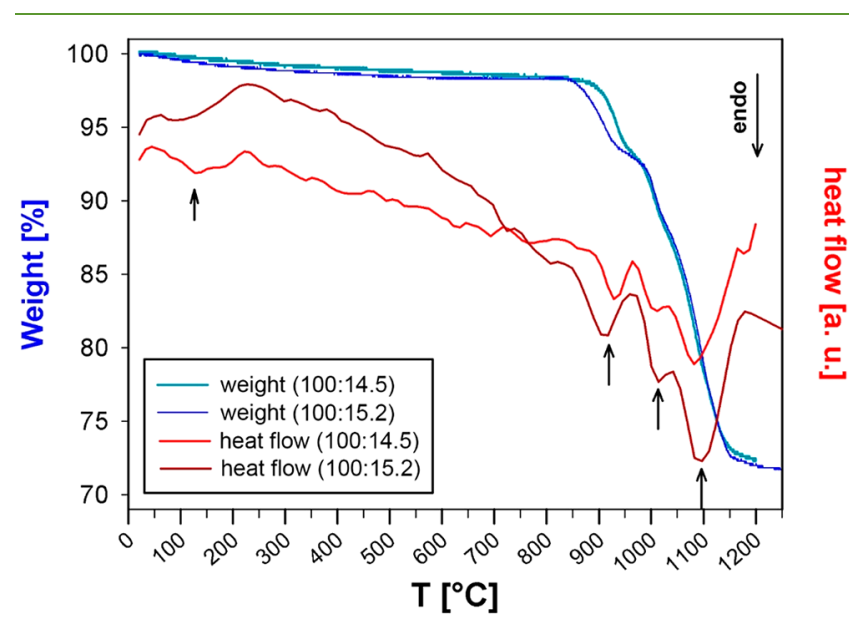

Figure 2. Simultaneous TGA and DTA profiles of $24 \mathrm{~h}$ ball milled mineral/C mixtures with composition 100:15.2 and 100:14.5.

maximum amount of carbon, that is, 100:14.5 (with a stoichiometric amount of C) and 100:15.2 mixtures. Quite similar profiles were obtained for mixtures with intermediate compositions (100:14.8 and 100:15). The broad endothermic peak at around $100{ }^{\circ} \mathrm{C}$ was due to moisture evaporation. The onset temperature of the carbothermic reduction was lower for the sample with the larger carbon black content (mineral/C = 100:15.2). In fact, the weight losses due to CO evolution and consequent reduction of 100:15.2 and 100:14.5 mixtures started at $\sim 850$ and $\sim 870{ }^{\circ} \mathrm{C}$, respectively. Three intense endothermic peaks at around 900,1000 , and $1100{ }^{\circ} \mathrm{C}$ were clearly visible.

Temuujin et al. reported that the reduction of wolframite:carbon mixtures, prepared by $2 \mathrm{~h}$ ball milling, showed 
an endothermic peak at $913{ }^{\circ} \mathrm{C}$ that was attributed to reaction 2:

$$
6 \mathrm{FeWO}_{4}+25 \mathrm{C} \rightarrow \mathrm{Fe}_{6} \mathrm{~W}_{6} \mathrm{C}+24 \mathrm{CO}
$$

$\mathrm{Fe}_{6} \mathrm{~W}_{6} \mathrm{C}$ then reacted with further carbon to form $\mathrm{Fe}$ and WC passing through intermediate $\mathrm{Fe}_{3} \mathrm{~W}_{3} \mathrm{C}$ : ${ }^{14}$

$$
\begin{aligned}
& \mathrm{Fe}_{6} \mathrm{~W}_{6} \mathrm{C}+\mathrm{C} \rightarrow 2 \mathrm{Fe}_{3} \mathrm{~W}_{3} \mathrm{C} \\
& \mathrm{Fe}_{3} \mathrm{~W}_{3} \mathrm{C}+2 \mathrm{C} \rightarrow 3 \mathrm{Fe}+3 \mathrm{WC}
\end{aligned}
$$

The carbothermic reduction of $\mathrm{CaWO}_{4}$ was extensively studied in the literature. ${ }^{12,13,15,20-24}$ The reduction is a two-stage process starting with reaction 5 , namely, the formation of tricalcium tungstate $\left(\mathrm{Ca}_{3} \mathrm{WO}_{6}\right)$ and $\mathrm{W}$, followed by reaction 6 , that is, the reduction of tricalcium tungstate to $\mathrm{W}$ and $\mathrm{CaO}$ :

$$
\begin{aligned}
& 3 \mathrm{CaWO}_{4(\mathrm{~s})}+6 \mathrm{C}_{(\mathrm{s})} \rightarrow \mathrm{Ca}_{3} \mathrm{WO}_{6(\mathrm{~s})}+2 \mathrm{~W}_{(\mathrm{s})}+6 \mathrm{CO}_{(\mathrm{g})} \\
& \mathrm{Ca}_{3} \mathrm{WO}_{6(\mathrm{~s})}+3 \mathrm{C}_{(\mathrm{s})} \rightarrow 3 \mathrm{CaO}_{(\mathrm{s})}+\mathrm{W}_{(\mathrm{s})}+3 \mathrm{CO}_{(\mathrm{g})}
\end{aligned}
$$

Finally, the carburization of metallic tungsten occurs via the intermediate ditungsten carbide, $\mathrm{W}_{2} \mathrm{C}$, formation: $\mathrm{W} \rightarrow \mathrm{W}_{2} \mathrm{C}$ $\rightarrow$ WC. ${ }^{25}$ The endothermic peaks associated with reactions 5 and 6 occur typically in the interval $1000-1150{ }^{\circ} \mathrm{C} .{ }^{21-23}$ Therefore, the three endothermic peaks we observed at approximately 900,1000 , and $1100{ }^{\circ} \mathrm{C}$ were attributable to reactions 2,5 , and 6 , respectively.

Furthermore, the TGA-DTA profiles showed that, under continuous heating conditions $\left(10^{\circ} \mathrm{C} / \mathrm{min}\right)$, the carbothermic reduction was practically complete at $1150-1200{ }^{\circ} \mathrm{C}$. On the basis of this information, we decided to synthesize WC powders by performing the carbothermic reduction at 1150 ${ }^{\circ} \mathrm{C}$.

Phase Detection. Figure 3 shows the XRD patterns of powders obtained after carbothermic reduction of mineral/C mixtures at $1150{ }^{\circ} \mathrm{C}$ (panel a) and after the subsequent twostep leaching treatments (panel b). As seen in Figure 3a, after 6 $\mathrm{h}$ at $1150{ }^{\circ} \mathrm{C}$ scheelite and ferberite phases were not detectable. Tricalcium tungstate, which forms according to reaction 5, was not detected, too. These findings suggest that, for all samples, complete reduction of the tungstates occurred. However, the reduction of tungstates is a necessary, but not sufficient, condition to convert the tungsten in the starting mineral into tungsten monocarbide. In powders prepared from mixtures 100:14.5, 100:14.8, and 100:15.0, undesired mixed carbide phases were visible, namely, $\mathrm{Fe}_{3} \mathrm{~W}_{3} \mathrm{C}$ and $\mathrm{FeW}_{3} \mathrm{C}$. Very weak peaks of metal tungsten were also present. The formation of mixed carbides ( $\eta$-phases) is a consequence of the incomplete carburization of tungsten contained in the wolframite that accompanied the scheelite in the concentrate we employed (see reactions 2-4). The low intensity peaks of $\mathrm{W}$ are ascribable to the incomplete carburization of metal tungsten formed upon the carbothermic reduction of scheelite (see reactions 5 and 6).

When the same heat treatment $\left(6 \mathrm{~h}\right.$ at $\left.1150{ }^{\circ} \mathrm{C}\right)$ was applied to the powder containing $15.2 \mathrm{~g}$ of carbon black per $100 \mathrm{~g}$ of tungsten concentrate (mixture 100:15.2), peaks of mixed carbides and/or $\mathrm{W}$ were not noticeable in the diffraction pattern. Therefore, we infer that a slightly larger carbon content than the stoichiometric one was necessary to ensure the full conversion of the tungsten in the ore concentrate into WC. Most likely, as recently suggested by Peng et al., ${ }^{26}$ an excess of carbon compensates the oxidation that occurred in the furnace due to reaction with moisture absorbed in the ball-
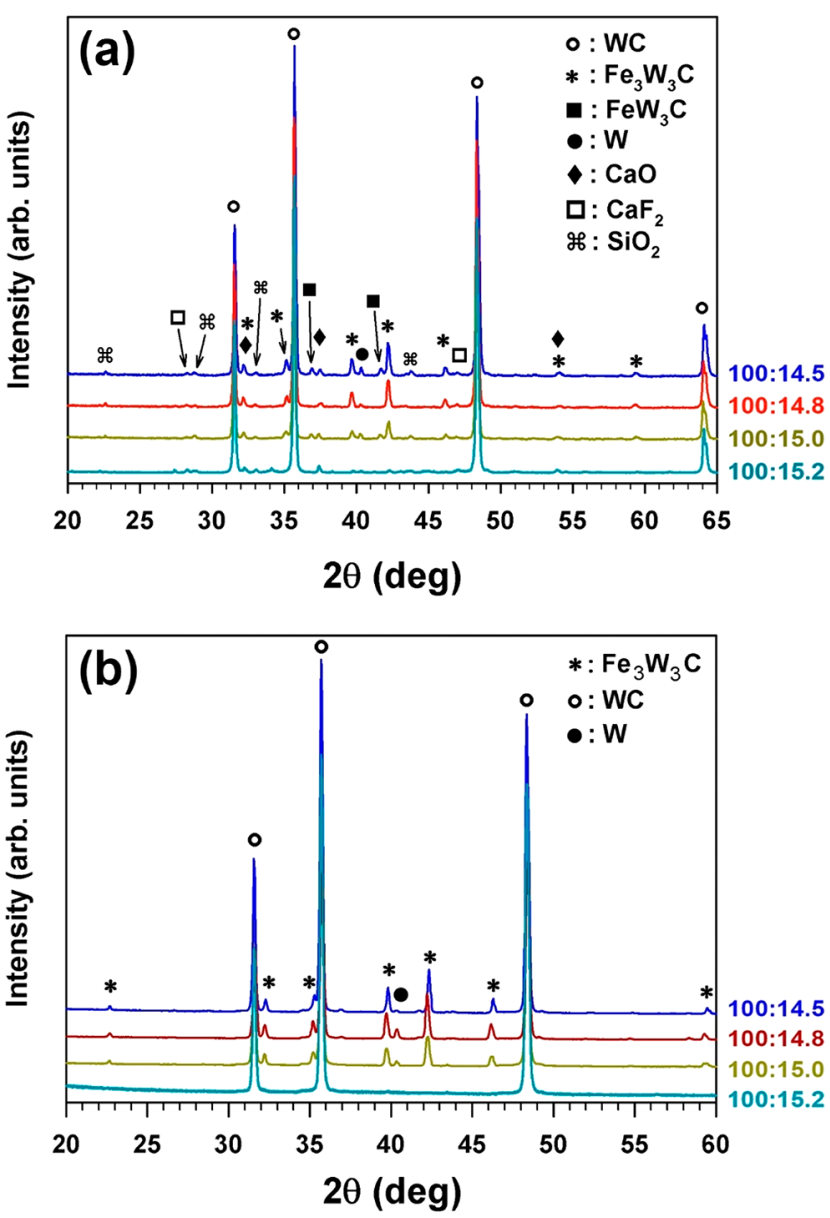

Figure 3. XRD patterns of powders prepared by carbothermic reduction of mineral/C mixtures (a) and after leaching treatments with $\mathrm{HCl}$ and $\mathrm{HF}$ (b). Mineral/C weight ratios were 100:14.5, $100: 14.8,100: 15.0$, and 100:15.2.

milled mixtures, or with traces of oxygen. Other phases detectable by XRD were $\mathrm{CaO}$ (coming from the carbothermic reduction of scheelite, and formed by reaction 6$), \mathrm{SiO}_{2}$, and fluorite $\left(\mathrm{CaF}_{2}\right)$ that could have originated probably at high temperature by reaction of calcium ions and fluorine compounds in the starting mineral ( $\mathrm{F}$ content was $0.88 \%$, see Table 1).

As seen in Figure $3 b$, as the carbon content increased, the amount of $\eta$-phases and metal tungsten in the WC powders purified by leaching decreased accordingly to the results of Figure 3a. It is worth noting that, after the prolonged leaching treatments with $\mathrm{HCl} 6 \mathrm{M}$ and $\mathrm{HF} 50 \%$, both $\mathrm{Fe}_{3} \mathrm{~W}_{3} \mathrm{C}$ and W, if noticeable after carbothermic reduction, were still detectable by XRD, with relative intensities quite similar to those in the as-reduced samples. These findings demonstrate that undesired $\mathrm{Fe}_{3} \mathrm{~W}_{3} \mathrm{C}$ and $\mathrm{W}$ phases could not be removed by the leaching treatments.

The effect of carbon content on phase purity of final WC powders is quite evident. As predictable from the phase compositions of powders prepared by carbothermic reduction using different amounts of carbon, phase pure WC powder was obtained from 100:15.2 mixture.

Morphological and Chemical Characterization of WC Powders. FEG SEM characterization of WC powders obtained after leaching of heat-treated mineral/C mixtures with weight ratios 100:14.5, 100:14.8, and 100:15.0 confirmed the presence 

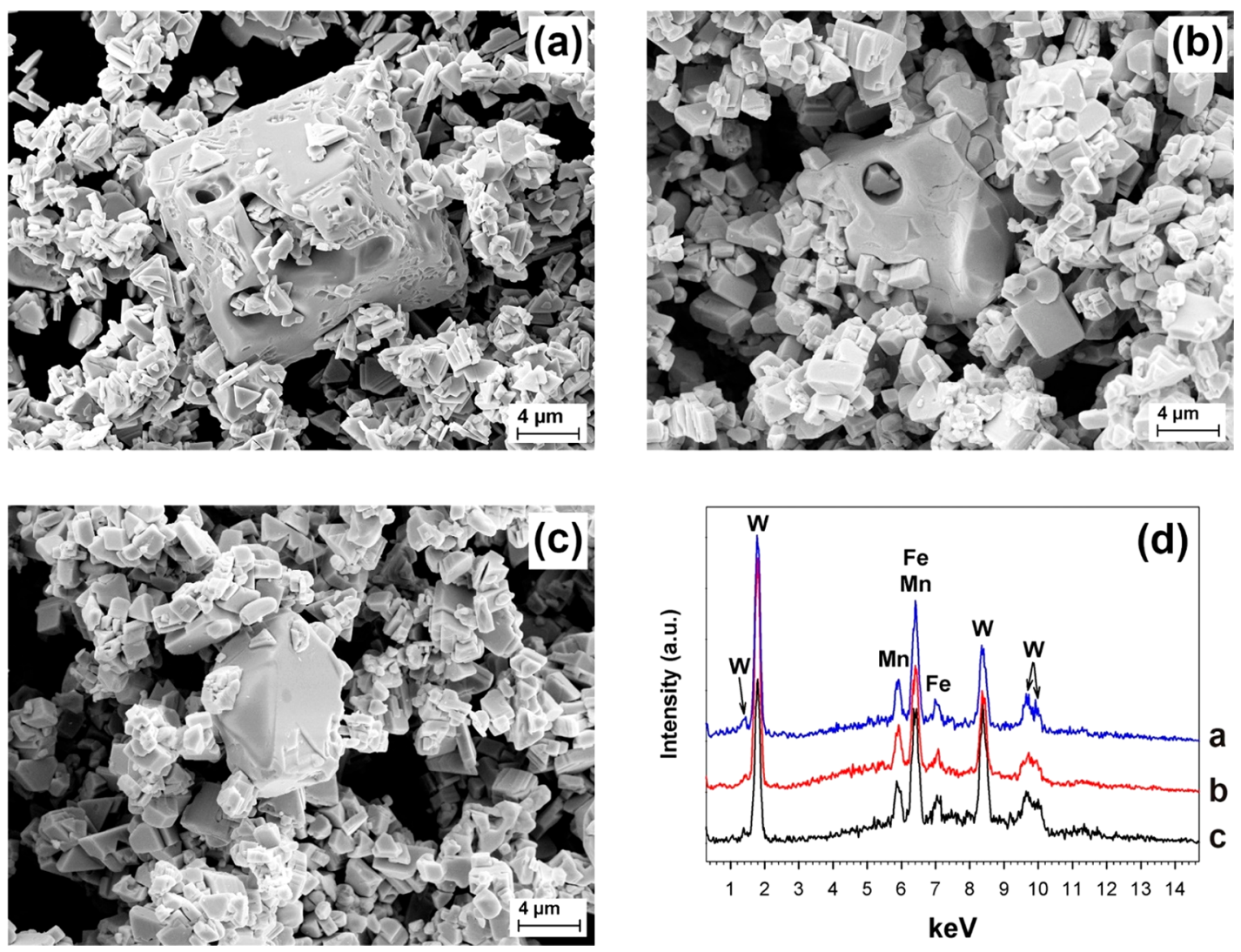

Figure 4. FEG SEM micrographs of mixed carbides ( $\eta$-phases) in WC powders synthesized from mineral/C mixtures 100:14.5 (a), 100:14.8 (b), and 100:15.0 (c). Panel (d) shows the spot EDS microanalyses of $\eta$-phases visible in panels (a), (b), and (c).
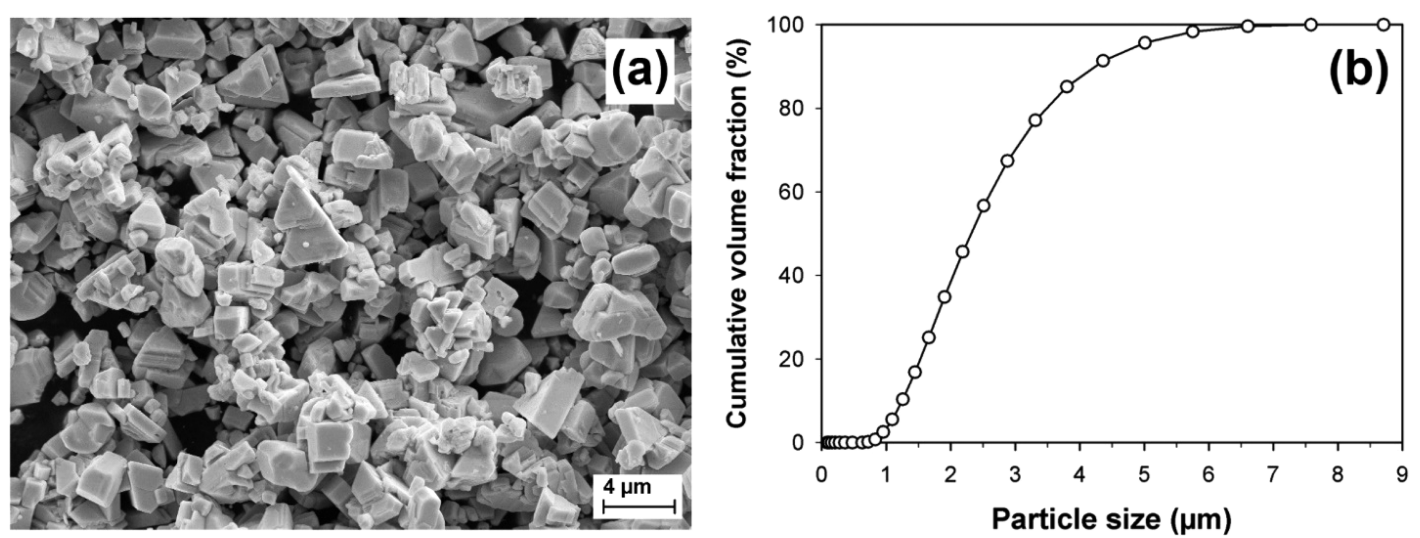

Figure 5. FEG SEM micrograph (a) and particle size distribution (b) of phase pure WC powders prepared from mixture mineral/C $=100: 15.2$ subjected to carbothermic reduction at $1150{ }^{\circ} \mathrm{C}(6 \mathrm{~h})$ and two leaching steps with $\mathrm{HCl} \sim 6 \mathrm{M}$ and $\mathrm{HF} 50 \%$.

Table 2. Impurities in Tungsten Carbide Powder Determined by ICP-AES

$\begin{array}{lllllllll}\text { element } & \mathrm{Fe} & \mathrm{Nb} & \mathrm{Sb} & \mathrm{Cr} & \mathrm{Ti} & \mathrm{Ta} & \mathrm{Al} & \mathrm{Mn} \\ \text { wt \% } & 0.212 & 0.131 & 0.062 & 0.061 & 0.052 & 0.051 & 0.040 & 0.033 \\ \text { element } & \mathrm{Mg} & \mathrm{Co} & \mathrm{Ca} & \mathrm{V} & \mathrm{Cu} & \mathrm{K} & \mathrm{Zr} & \mathrm{Ni} \\ \text { wt \% } & 0.024 & 0.024 & 0.020 & 0.008 & 0.008 & 0.006 & 0.004 & 0.002\end{array}$

of mixed carbides detected by XRD. Figure 4 displays WC grains, with typical prism shape, surrounding much larger particles placed in the center of the frame. The spot EDS microanalyses in Figure 4d indicated that those larger particles were mixed carbide phases containing $\mathrm{W}, \mathrm{Fe}$, and $\mathrm{Mn}$.

As previously discussed, these $\eta$-phases were formed during carbothermic reduction of wolframite, which is a solid solution of ferrous tungstate and manganous tungstate, $\mathrm{Fe}_{1-x} \mathrm{Mn}_{x} \mathrm{WO}_{4}$. Consequently, reactions 2 and 3 should be written more properly as

$$
6 \mathrm{Fe}_{1-x} \mathrm{Mn}_{x} \mathrm{WO}_{4}+25 \mathrm{C} \rightarrow \mathrm{Fe}_{6(1-x)} \mathrm{Mn}_{6 x} \mathrm{~W}_{6} \mathrm{C}+24 \mathrm{CO}
$$




$$
\mathrm{Fe}_{6(1-x)} \mathrm{Mn}_{6 x} \mathrm{~W}_{6} \mathrm{C}+\mathrm{C} \rightarrow 2 \mathrm{Fe}_{3(1-x)} \mathrm{Mn}_{3 x} \mathrm{~W}_{3} \mathrm{C}
$$

In Figure 5a the FEG SEM micrograph of phase pure WC, prepared from mineral $/ \mathrm{C}=100: 15.2$ mixture, is displayed. The median size (d50) was $2.38 \mu \mathrm{m}$ (Figure 5b), as measured with a laser particle size analyzer (Mastersizer 2000, Malvern Panalytical Ltd.).

The content of impurities in this powder was determined by ICP-AES. The results are shown in Table 2. The data indicate that $\mathrm{Fe}$ and $\mathrm{Nb}$ were the only impurities exceeding $0.1 \mathrm{wt} \%$, and that the tungsten carbide purity was $99 \%$. This powder was used for preparing sintered hard metal samples.

Sintered Hard Metal. To prepare sintered hard metal, we started from $2.89 \mathrm{~kg}$ of tungsten concentrate $\left(69.9 \% \mathrm{WO}_{3}\right)$. After carbothermic reduction and lab scale leaching treatments, filtration, rinsing, and unavoidable losses of material, we obtained $1.56 \mathrm{~kg}$ of purified WC, corresponding to a remarkable $92 \%$ extraction yield. $92 \mathrm{WC}-8 \mathrm{Co}$ (wt \%) cemented tungsten carbide was prepared according to the procedure detailed in Materials and Methods. Figure 6 shows

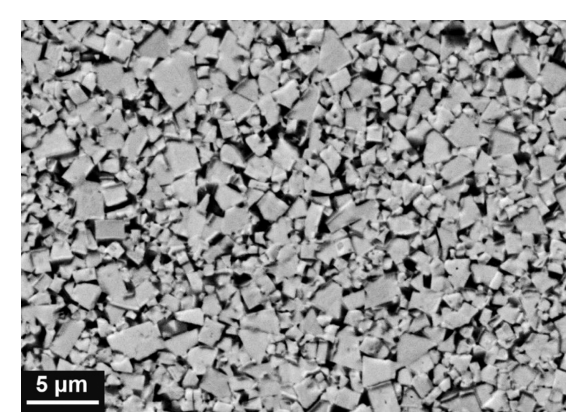

Figure 6. Microstructure of the prepared 92WC-8Co sintered hard metal.

the FEG SEM micrograph, acquired using backscattered electrons (BSE) signal, of the sintered hard metal. The density was $14.662 \mathrm{~g} / \mathrm{cm}^{3}$, corresponding to $99.1 \%$ fractional density.

The hardness and fracture toughness were measured as HV $=1487 \pm 15 \mathrm{kgf} / \mathrm{mm}^{2}, \mathrm{HRA}=91.5$, and $K_{\mathrm{IC}}=14.6 \mathrm{MPa} \cdot \mathrm{m}^{1 / 2}$, as indicated by the black triangle in Figure 7 . For comparison,

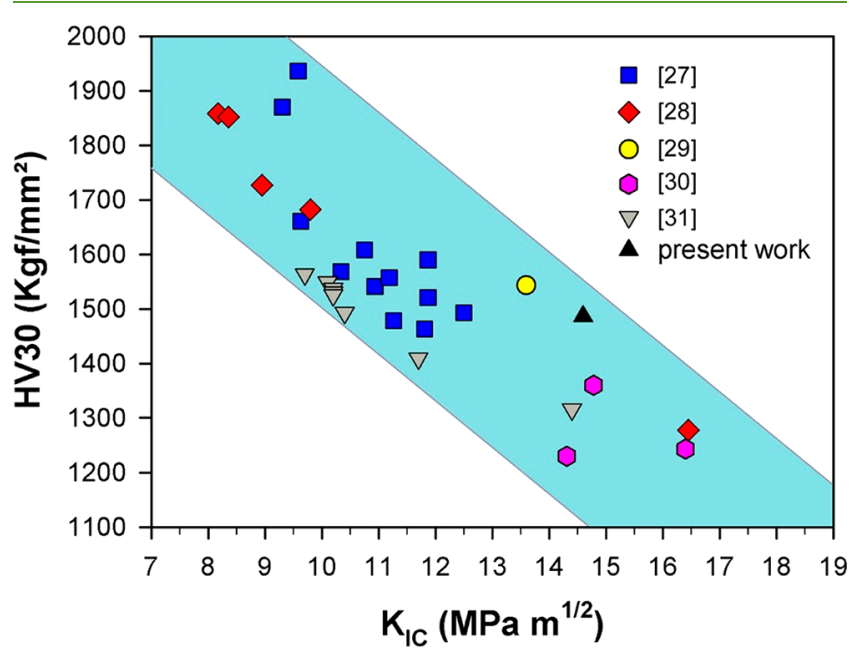

Figure 7. Comparison of the hardness and fracture toughness between the present WC-Co hard metal and those reported in the literature.
Vickers hardness and $K_{\mathrm{IC}}$ values of WC-Co composites having binder contents in the range 4-12 wt \% and that have been reported in the relevant literature ${ }^{27-31}$ are also shown in Figure 7.

A general inverse relationship between hardness and toughness is observed for conventional hard metals, that is, WC-Co composites that are not nanostructured.

For these materials, hardness decreases with increasing cobalt content and WC grain size; fracture toughness increases with Co content and with WC grain size. ${ }^{32}$

However, at a certain hardness, the toughness of a specific hard metal grade, characterized by WC grain size and Co percentage, may vary significantly, depending on several parameters, including sintering temperature, sintering time, and the presence of specific grain growth inhibitors (e.g., VC, $\mathrm{Cr}_{3} \mathrm{C}_{2}$ ).

The band of Figure 7 does represent such variability within the general trend. Alloys which are near the right borderline in Figure 7 represent good hardness/toughness combination, in that they have a larger toughness value for a given hardness.

The hard metal we obtained by sinter-HIP falls in the right portion of the plot, showing a favorable toughness value. Therefore, these findings validate for the first time the carbothermic reduction of tungstate concentrates as a viable route for the synthesis of WC powders that can be surely employed for hard metal manufacturing.

Comparison of the Proposed and Conventional Processes. After having evaluated the suitability of WC powders obtained directly from enriched ore for the production of hardmetal products, we now analyze whether, and to what extent, the synthesis of WC powders by carbothermic reduction is convenient from the environmental impact point of view, in terms of both energy demand and production of industrial effluents with respect to the process currently used in the tungsten industry via APT.

One of the first analyses of the APT production process was carried out by Vadasdi, ${ }^{33}$ who concluded that the process is among the most complex and polluting hydrometallurgical processes (2-4 times higher than that for $\mathrm{Ni}$ or $\mathrm{Cu})$. A more recent paper by X. Ma et al. ${ }^{8}$ reports a Life-Cycle Assessment (LCA) study of tungsten carbide production via APT showing that this synthetic route is responsible for environmental burdens derived from carcinogens, ecotoxicity, climate change and fossil depletion. The main streams of reagent and effluents of this process are presented in the simplified material balance of Figure 8. According to these authors, the total electric energy demand for producing 1 ton of WC from the tungsten concentrate via APT is 16.2 MWh. Most of this energy (15.51 $\mathrm{MWh} / \mathrm{t}$ ) comes from the pyrometallurgical conversion of APT into WC. Similar energy values are given in refs 7 and 33 .

About the direct synthesis of tungsten carbide from tungsten concentrate ore, only laboratory data are available. The simplified material balance of the process is reported in Figure 9, while a more detailed scheme is reported in Figure S1 of the Supporting Information. Figure 10 shows the contribution of each process step to the energy balance.

The two most critical steps in the estimation of the overall energy demand are (i) the comminution and intimate mixing of concentrate ore with carbon black and (ii) the carbothermic reduction. The former is calculated considering that only tungsten ore is comminuted from 300 to $2 \mu \mathrm{m}$, while the carbon black is already supplied as fine powder with an average size of $0.2-0.3 \mu \mathrm{m}$. The contribution of carbon black in this 


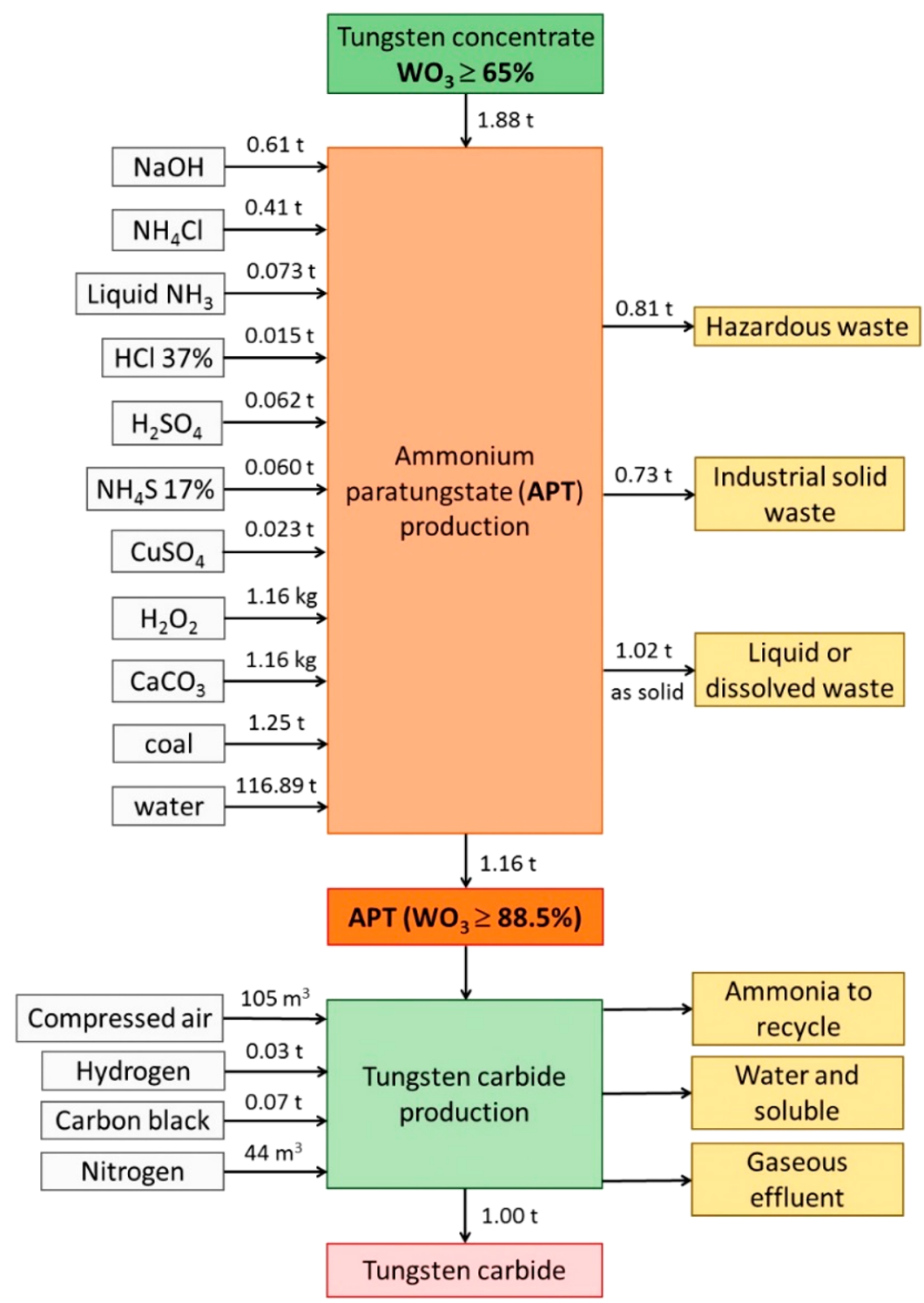

Figure 8. Simplified material balance of the production of tungsten carbide via APT. ${ }^{8}$

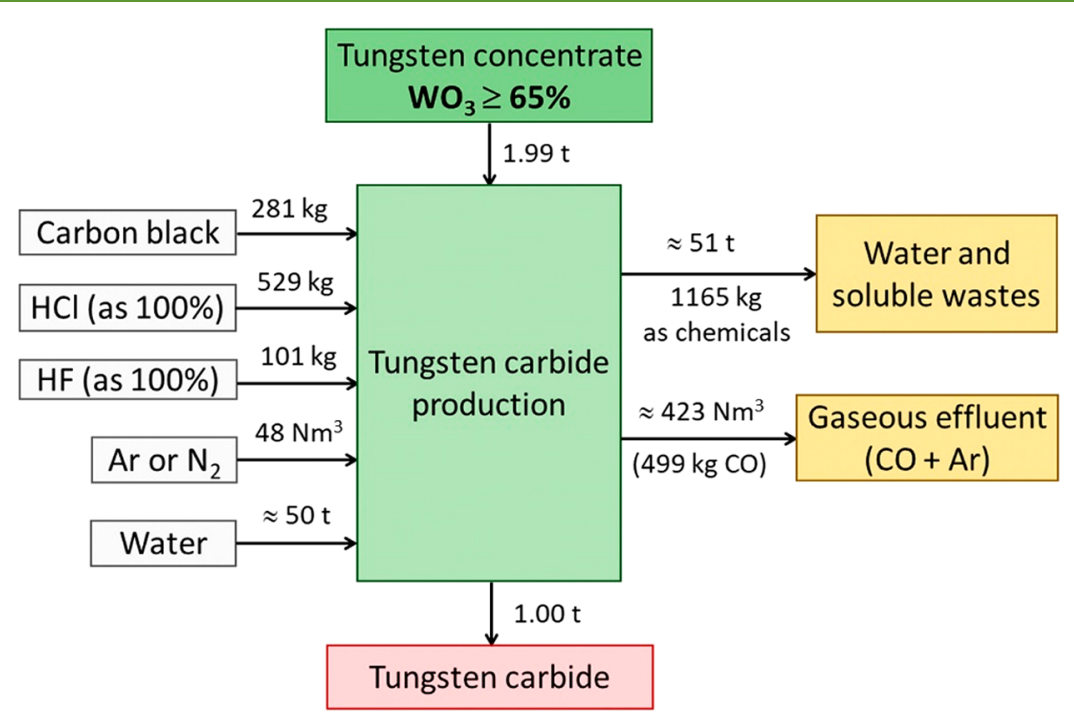

Figure 9. Simplified material balance of the direct synthesis of tungsten carbide powders by carbothermic reduction of tungsten concentrate and subsequent two-step leaching. 


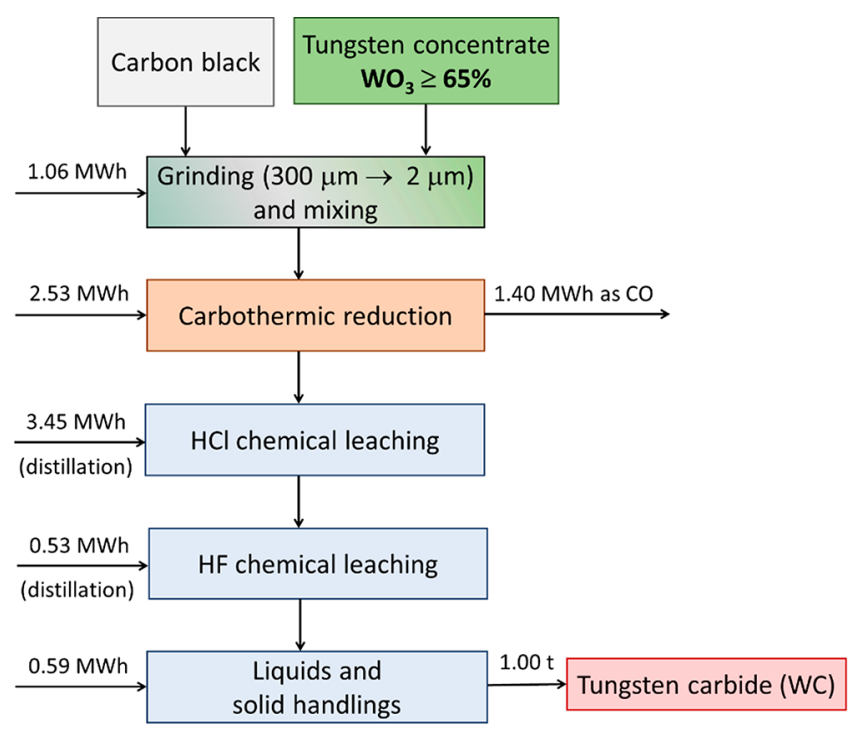

Figure 10. Contribution of each step to the energy balance of the direct synthesis of tungsten carbide powders by carbothermic reduction of tungsten concentrate.

calculation is only in the total weight of material. With this assumption, the total energy required for this step is 1065 $\mathrm{kWh}$. For the latter process, the following contributions must be taken into account (per ton of WC): heat absorbed from the reaction equal to $989 \mathrm{kWh}$, energy necessary to bring compounds to $1150{ }^{\circ} \mathrm{C}$ equal to $397 \mathrm{kWh}$, energy for the eating of the furnace from 25 to $1150{ }^{\circ} \mathrm{C}$ equal to $560 \mathrm{kWh}$, and energy losses during the process (30\% of the total energy demand) equal to $584 \mathrm{kWh}$.

The details of the calculations of the first two steps are given in the Supporting Information. Other energy is necessary in the leaching steps conducted with $\mathrm{HCl} 20.22$ wt \% ( $\approx 6 \mathrm{M})$ at the boiling temperature $\left(109{ }^{\circ} \mathrm{C}\right.$ ) and with HF $50 \mathrm{wt} \%$ (at room temperature). Following the experimental laboratory procedure, these steps are conducted with an excess of acid that needs to be recovered by distillation.

In our simulation, an amount of acid three times the stoichiometric value was considered in both the leaching steps. With the adopted conditions, the energy required for recovering all the unreacted $\mathrm{HCl}$ and $\mathrm{HF}$ at the target concentration (20.22 and $50 \mathrm{wt} \%$, respectively) can be estimated in the order of $3.45 \mathrm{MWh}$ for the recovery of $\mathrm{HCl}$ and $0.53 \mathrm{MWh}$ for HF. This energy is increased $15 \%$ to take into account the energy required for material handling (0.59 MWh).

The total estimated energy demand of the process is 8.16 MWh per ton of WC, without considering any optimization and scale-up of the industrial process. This value is about half the energy required to produce 1 ton of $\mathrm{WC}$ via APT. The process can further benefit from the gaseous flow of $\mathrm{CO}$ that can be used as a fuel in the plant, thereby reducing the energy demand by an additional $1.40 \mathrm{MWh}$, or for the production of over $83 \mathrm{~kg}$ of hydrogen through the water gas shift reaction. If we consider the energy produced by $\mathrm{CO}$ combustion, the overall energy demand of the new process reduces to 6.76 $\mathrm{MWh} / \mathrm{t}$, that is, a $58 \%$ energy saving with respect to the route currently employed in the tungsten industry.

The lower energy demand of the direct synthesis process results also in a reduced amount of $\mathrm{CO}_{2}$ emissions. By assuming the European emission factor for energy generation $\left(295.7 \mathrm{~g} \mathrm{CO}_{2} / \mathrm{kWh}_{\mathrm{e}}\right)^{34}$ and the amount of $\mathrm{CO}_{2}$ from the reaction (after $\mathrm{CO}$ oxidation), the carbothermic reduction does result in reduction of about $34 \% \mathrm{CO}_{2}$ emission per ton of WC.

Finally, the direct synthesis of tungsten carbide by carbothermic reduction of the enriched ore is not only characterized by a lower energy demand compared to the traditional process, but also by a particularly reduced inventory of reactants ( 4 vs 14) that are used in a reduced amount (less than half, if considered in absolute form). As a result, the quantities of hazardous and solid wastes $(1165 \mathrm{~kg}$ per 1 ton WC) are also more limited, being less than half those of the APT process.

\section{CONCLUSIONS}

Tungsten carbide (WC) powders were obtained directly by carbothermic reduction of tungsten concentrate and subsequent leaching steps.

These powders are suitable for the production of quality hard metals (sintered WC-Co composites). In fact, WC-Co composites prepared by sinter-HIP show properties (fractional density, hardness, and toughness) appropriate for industrial use.

This technology is reverse of the hydrometallurgical route currently employed in the tungsten industry. Here synthesis is done first and then impurities are removed by leaching.

This approach has distinct advantage of its simplicity with minimal processing. Compared to the hydro- and pyrometallurgical routes (mineral $\rightarrow \mathrm{APT} \rightarrow \mathrm{WO}_{3} \rightarrow \mathrm{W} \rightarrow \mathrm{WC}$ ), this process allows about $50 \%$ energy saving, $-34 \% \mathrm{CO}_{2}$ emissions, and significantly lower amounts of hazardous and industrial wastes.

These figures validate the carbothermic reaction as a viable route for energy efficient and lower environmental impact production of WC powders, which represent $>50 \%$ of the world tungsten demand.

\section{ASSOCIATED CONTENT}

\section{Supporting Information}

The Supporting Information is available free of charge at https://pubs.acs.org/doi/10.1021/acssuschemeng.1c01286.

Details of materials balance and energy requirement for the carbothermic reduction of enriched tungsten ore. Material balance of the direct synthesis of tungsten carbide powders by carbothermic reduction of tungsten concentrate and subsequent two-step leaching (Figure S1). Enthalpies of formation of reactants and products involved in the reaction (Table S1) (PDF)

\section{AUTHOR INFORMATION}

\section{Corresponding Author}

Riccardo Polini - Dipartimento di Scienze e Tecnologie Chimiche, Università degli Studi di Roma "Tor Vergata", Via della Ricerca Scientifica, 00133 Rome, Italy; (1) orcid.org/ 0000-0002-6551-0883; Phone: +39 067259 4414; Email: polini@uniroma2.it; Fax: +390672594328

\section{Authors}

Andrea Marcucci - Dipartimento di Scienze e Tecnologie Chimiche, Università degli Studi di Roma "Tor Vergata", Via della Ricerca Scientifica, 00133 Rome, Italy 
Cadia D'Ottavi - Dipartimento di Scienze e Tecnologie Chimiche, Università degli Studi di Roma "Tor Vergata", Via della Ricerca Scientifica, 00133 Rome, Italy

Patrizia Nunziante - Dipartimento di Scienze e Tecnologie Chimiche, Università degli Studi di Roma "Tor Vergata", Via della Ricerca Scientifica, 00133 Rome, Italy

Paolo De Filippis - Dipartimento di Ingegneria Chimica, Materiali, Ambiente, Sapienza Università di Roma, 00184 Rome, Italy

GianCarlo Marcheselli - Fabbrica Italiana Leghe Metalliche Sinterizzate (F.I.L.M.S.) SpA, 28877 Anzola d'Ossola, Italy

Complete contact information is available at:

https://pubs.acs.org/10.1021/acssuschemeng.1c01286

\section{Notes}

The authors declare no competing financial interest.

\section{REFERENCES}

(1) Foucaud, Y.; Filippov, L.; Filippova, I.; Badawi, M. The Challenge of Tungsten Skarn Processing by Froth Flotation: A Review. Front. Chem. 2020, 8, 230.

(2) Shen, L.; Li, X.; Lindberg, D.; Taskinen, P. Tungsten extractive metallurgy: A review of processes and their challenges for sustainability. Miner. Eng. 2019, 142, 105934.

(3) Yang, X. Beneficiation studies of tungsten ores - A review. Miner. Eng. 2018, 125, 111-119.

(4) Lassner, E., Schubert, W.-D. Tungsten - Properties, Chemistry, Technology of the Element, Alloys, and Chemical Compounds; Kluwer Academic/Plenum Publishers: New York, 1999.

(5) Zbranek, V.; Zbranek, Z.; Burnham, D. A. Process for recovering high purity tungsten compositions from wolframite ores. U.S. Patent 4092400, 1978.

(6) Singh Gaur, R. P. Modern hydrometallurgical production methods for tungsten. JOM 2006, 58, 45-49.

(7) Leal-Ayala, D. R.; Allwood, J. M.; Petavratzi, E.; Brown, T. J.; Gunn, G. Mapping the global flow of tungsten to identify key material efficiency and supply security opportunities. Resour. Conserv. Recycl. 2015, 103, 19-28.

(8) Ma, X.; Qi, C.; Ye, L.; Yang, D.; Hong, J. Life cycle assessment of tungsten carbide powder production: A case study in China. J. Cleaner Prod. 2017, 149, 936-944.

(9) Wang, K.-F.; Sun, G. D.; Wu, Y.-D.; Zhang, G.-H. Fabrication of ultrafine and high-purity tungsten carbide powders via a carbothermic reduction-carburization process. J. Alloys Compd. 2019, 784, 362369.

(10) Wang, K.-F.; Sun, G.-D.; Wu, Y.-D.; Zhang, G.-H.; Chou, K. C. Size-controlled synthesis of hig-purity tungsten carbide powders via a carbothermic reduction-carburization process. Int. J. Refract. Met. Hard Mater. 2019, 84, 104975.

(11) https://www.un.org/sustainabledevelopment/developmentagenda/ (accessed December 28, 2020).

(12) Welham, N. J. Formation of micronized WC from scheelite (CaWO 4$)$. Mater. Sci. Eng., A 1998, 248, 230-237.

(13) Welham, N. J. Novel Route to Submicrometer Tungsten Carbide. AIChE J. 2000, 46, 68-71.

(14) Temuujin, J.; Senna, M.; Jadambaa, T.; Byambasuren, D. Direct Synthesis of Tungsten Carbide nanoparticles by Mechanically Assisted Carbothermic Reduction of Natural Wolframite. J. Am. Ceram. Soc. 2005, 88 (4), 983-985.

(15) Singh, H.; Pandey, O. P. Direct synthesis of nanocrystalline tungsten carbide from scheelite ore by solid state reaction method. Ceram. Int. 2013, 39, 785-790.

(16) Liu, W.; Song, X.; Wang, K.; Zhang, J.; Zhang, G.; Liu, X. A novel rapid route for synthesizing WC-Co bulk by in situ reactions in spark plasma sintering. Mater. Sci. Eng., A 2009, 499, 476-481.

(17) Perry, R. H. Section 8: Size Reduction and Size Enlargement. Chemicals Engineering Handbook, 6th ed.; MacGraw Hill, 1984.
(18) https://www.911metallurgist.com/blog/table-of-bond-workindex-by-minerals (accessed February 07, 2021).

(19) Barin, I. Thermochemical Data of Pure Substances, 3rd ed.; VCH: Weinheim; New York, 1995.

(20) Johnston, R. F.; Nguyen, H. T. Direct reduction carburization of scheelite with carbon. Miner. Eng. 1996, 9, 765-773.

(21) Polini, R.; Palmieri, E.; Marcheselli, G. Nanostructured tungsten carbide synthesis by carbothermic reduction of scheelite: A comprehensive study. Int. J. Refract. Met. Hard Mater. 2015, 51, 289300.

(22) Polini, R.; Palmieri, E.; Marcheselli, G. Effect of carbon excess and milling conditions on the synthesis of nanostructured WC by carbothermic reduction of scheelite $\left(\mathrm{CaWO}_{4}\right)$. Int. J. Refract. Met. Hard Mater. 2016, 54, 178-185.

(23) Palmieri, E.; Marcucci, A.; Marcheselli, G.; De Stefanis, A.; Polini, R. Carbothermic reduction of scheelite $\left(\mathrm{CaWO}_{4}\right)$ doped with cobalt or nickel. Int. J. Refract. Met. Hard Mater. 2016, 59, 93-99.

(24) Polini, R.; Marcucci, A.; Palmieri, E.; Marcheselli, G. Size tailoring of WC particles in the carbothermic reduction of scheelite $\left(\mathrm{CaWO}_{4}\right)$. Int. J. Refract. Met. Hard Mater. 2017, 64, 75-82.

(25) Mühlbauer, G.; Kremser, G.; Bock, A.; Weidow, J.; Schubert, W.-D. Transition of $\mathrm{W}_{2} \mathrm{C}$ to WC during carburization of tungsten metal powder. Int. J. Refract. Met. Hard Mater. 2018, 72, 141-148.

(26) Peng, Y.; Wang, H.; Zhao, C.; Hu, H.; Liu, X.; Song, X. Nanocrystalline WC-Co composite with ultrahigh hardness and toughness. Composites, Part B 2020, 197, 108161.

(27) Schubert, W. D.; Neumeister, H.; Kinger, G.; Lux, B. Hardness to toughness relationship of fine-grained WC-Co hardmetals. Int. J. Refract. Met. Hard Mater. 1998, 16, 133-142.

(28) Jia, K.; Fischer, T. E.; Gallois, B. Microstructure, hardness and toughness of nanostructured and conventional WC-Co composites. Nanostruct. Mater. 1998, 10, 875-891.

(29) Zhao, S. X.; Song, X. Y.; Zhang, J. X.; Liu, X. M. Effect of scale combination and contact condition of raw powders on SPS sintered near-nanocrystalline WC-Co alloy. Mater. Sci. Eng., A 2008, 473, 323-329.

(30) Zheng, Z.; Ke, Y.; Zhang, G.; Ding, Q.; Zhang, J.; Wu, H.; Xu, X.; Lu, X.; Zhu, X. Microstructure and mechanical properties of dualgrain structured WC-Co cemented carbides. Ceram. Int. 2019, 45, 21528-21533.

(31) De Gaudenzi, G. P.; Tedeschi, S. Effetto della granulometria del WC sulle prestazioni del metallo duro. La Metallurgia Italiana 2017, 11/12, 24-38.

(32) Oyama, S. T., Ed. The Chemistry of Transition Metal Carbides and Nitrides; Blackie Academic \& Professional: Glasgow, U.K., 1996.

(33) Vadasdi, K. Effluent-Free Manufacture of Ammonium Paratungstate (APT) by Recycling the Byproducts. Int. J. Refract. Met. Hard Mater. 1995, 13, 45-59.

(34) $\mathrm{CO}_{2}$ Intensity of Electricity Generation. Available at the following web site: https://www.eea.europa.eu/data-and-maps/data/ co2-intensity-of-electricity-generation (accessed February 07, 2021). 